\title{
Towards a process-based typology of workplace coaching: An
}

\section{empirical investigation}

\author{
Adrian Myers and Tatiana Bachkirova \\ Oxford Brookes University
}

\begin{abstract}
Research into work-based coaching has been led by the need of a new discipline to demonstrate effectiveness of this practice, often assuming that coaching is a homogeneous activity. A multifaceted and multi-purposeful nature of coaching now requires development of meaningful typologies that reflect this diversity and grounded in the analysis of coaching process. There are many reasons empirical investigations of the coaching process are extremely rare. The aim of this article is to present such a study leading to an empirically derived model representing a 4demensional coaching typology. The research was based on a 'qualiquantological' $\mathrm{Q}$ methodology involving 47 participants. Actual coaching sessions were evaluated from the perspective of professional coaches, their clients and professional coaches observing recordings of these sessions. A Q methodological factor analysis led to a clear identification of two types of coaching: 'Client-led coaching' in which the coach and client work together in a flowing dialogue exploring the client's issues and 'Process-led coaching,' characterized by an actively engaged coach using a wide range of coaching techniques, visibly structuring the coaching process. There was partial support for a third type of 'Dialogic Coaching' and a fourth approach was inferred as being the inverse type of client-led coaching.
\end{abstract}

\section{Keywords:}

Workplace coaching, Executive Coaching, Coaching Process Research, Q methodology, Coaching Process Q Sort 


\section{Introduction}

The professional practice of workplace coaching grew organically in response to the needs of organisations to provide individually focused support for diverse groups of employees (Bachkirova, Spence, \& Drake, 2017). This bottom-up development process has been positive overall with growing evidence that coaching is "a mainstream activity in organizations worldwide" (Grant, 2013, p.15) and reports that there are now 53,300 practising coaches worldwide (International Coach Federation, 2016). However, the conceptualization of this practice has been seriously behind this utilization process (Ellinger \& Kim, 2014; Cox, Bachkirova, \& Clutterbuck, 2014a). Even a definition of workplace coaching continues to be an issue because of the diversity of coaching styles, contexts and applications (Bachkirova \& Kauffman, 2009). We will use a reasonably generic definition from a well-known handbook describing coaching as "a human development process that involves structured, focused interaction and the use of appropriate strategies, tools and techniques to promote desirable and sustainable change for the benefit of the client and potentially for other stakeholders" (Cox et al., 2014b, p. 1).

The theoretical base of the discipline of coaching is heavily dependent on neighbouring disciplines such as mentoring and counselling and relevant theories in core disciplines such as psychology, sociology and organizational studies (Cox et al., 2014a; Bachkirova, 2017). This multiplicity of influences has led to a highly eclectic use of theory in coaching thus creating an impression of "an unnecessary mystique" about its theoretical base (Cox et al 2014a, p. 140) and even a justified concern of coaching being atheoretical (Peltier, 2009; Hamlin, Ellinger, and Beattie, 2008). Cox et al. (2014a) argued that as much as coaching can be a powerful ally, for example in HRD, its rich but inconsistent discourses in description of coaching services create a difficult task for HR professionals and particularly buyers of coaching to judge the relevance of 
numerous traditions of coaching and evaluate them for their organizational agendas (Robson, 2011; Egan, 2013).

As far as research is concerned, being a new discipline with a need to establish its place in the organizational arena has been a significant factor in the agenda for coaching research to 'prove that coaching works'. Therefore, the emphasis in research activities has been for some time on outcome studies and their number is steadily growing (e.g., Olivero, Bane, \& Kopelman, 1997; Bowles, Cunningham, \& de la Rosa \& Picano, 2007; Smither, London, Flautt, Vargas, \& Kucine 2003; Mackie, 2015, de Haan, Duckworth, Birch, \& Jones, 2013). Although these studies and their systematic analysis (e.g., Grant, 2012; Theeboom, Beersma, and van Vianen, 2014; Jones, Woods, \& Guillaume, 2016; Greif, 2017) confirm that coaching can be effective in some specific contexts, there are many issues associated with the diversity of coaching approaches which create obstacles for development of the evidence base for coaching. According to Grant (2013, p. 34) “onlookers struggle to make sense of the potentially amorphous mass of data". The diversity refers not only to the many contexts of application and varied outcome measures but also to the enormous variety of ways to coach, thus making outcome studies difficult to compare and to develop reliable implications. The lack of conceptualization of coaching at least in relation to types of coaching affects the value of such studies for further development of the coaching discipline. What seems important at tis stage is a research focus on the empirical investigation of the coaching process: the interpersonal interaction between coach and client with an intention to establish patterns in the way coaching is conducted: a typology of coaching.

There has recently been a strong call in the coaching discipline to expand the attention of researchers to understanding the process of coaching, to have a rich description of the coaching interaction, to explore the main parameters of coaching that make a difference and to identify them within different coaching types and variations of practice: the identification of 
the "active ingredients" (Bono et al, 2009, p. 393) of the coaching process. These could include the observable behaviours occurring between coach and client, the tasks and activities which are conducted and the broader phenomenological and meaning-making process occurring between coach and client (Bachkirova et al, 2015). It must be said that the literature on the coaching process is not entirely absent, but it consists of opinion-based texts by practitioners (e.g. Rogers, 2012; Wilson, 2007) and a few handbooks that tend to faithfully describe differences in coaching process as a reflection of a variety of theoretical approaches usually following main therapeutic traditions (e.g. Palmer and Whybrow, 2007; Cox et al, 2014b). At the same time, the reality of the practice shows that coaches tend to identify with these traditions only loosely and develop their own approaches to practice (Clutterbuck, 2010). Therefore, it is not just that a meaningful typology of coaching is needed, but it must derive from the actual practice of coaching, from what coaching process is like. The number of empirical studies on the coaching process is however limited for some obvious reasons such as the willingness of the participants to be observed in a real session and the possible effect of intrusion on the relationship.

An additional challenge that coaching process researchers face is the decisions that must be made about whose perspectives are the most relevant/informative in the assessment of what is happening in the coaching session. A particularly challenging distinction is between on the one hand, the coach's and client's first-person perspective and on the other hand, the observers' perspective of the same session. This distinction has serious implications not only for research but also for practice, policies and the education of coaches. It seems reasonable to assume that a typology of coaching process must be based on multi-perspective research but research to date is lacking. The third person perspective is a challenge for various ethical reasons. Although some elements of the session have been studied from the observer perspective (Greif, 2010), there has been no attempt to analyse real sessions in their entirety. 
This study is therefore an empirical investigation into the coaching process from multiple perspectives of the coach, client and observers. Building on the structural analysis of the coaching engagement that includes elements of the coach and client as individuals, context of the engagement, relationship and coaching processes (Cox et al., 2014a), we will focus on the latter by taking as a unit of analysis a whole coaching session. This position reflects our view on coaching as a two-way process between the coach and client rather than a series of actions performed by the coach. This is a relational and constructivist conceptualisation of the coaching process. Accordingly, this study aims to provide coaches, clients, sponsors, educators and supervisors with rich description of the complexity of the interaction between coach and client and identify patterns that can be used in reflecting on coaching sessions. This reflective process can lead coaches to consider how they might or actually work with clients, the implications of this and the need to change. At the same time, arriving at a typology of coaching may advance theoretical understanding of the coaching process and differentiation of it from other practices such as counselling or consultancy (Bachkirova and Kauffman, 2009).

\section{Theoretical background}

In the coaching and wider literature there are many concepts, models and theoretical propositions that claim the importance of the interactive nature of the coaching engagement and thus a focus on the coaching relationship and the nature of the coaching conversation. In the conceptualization of the coaching engagement by Cox et al (2014a), processes and relationship are one of the four essential and equally important elements; the other three being characteristics and attitudes of the coach and client and the environmental factors of the context. Coaching is viewed as "a type of extended cognition, an alliance, where a new piece of knowledge may result in either a new explanation or is used to fill a gap in an existing explanation, but where both help the alliance to move a little closer to a more complete 
understanding of the task and its resolution" (2014a, p. 143). The elements of the process are generally associated with learning and with good communication and include listening, clarifying and mutually enhanced reflection. In addition to learning, this conceptualization also emphasises the importance of the coaching relationship (e.g., de Haan, 2008).

Differently to seeing coaching as a relational and learning process (Cox, 2013; Kemp, 2008), there are other conceptualizations of coaching process. Gessnitzer \& Kauffeld (2015) for example suggest that the coaching is essentially relational (de Haan, 2008). They consider the quality of relationship as the most important success factor in the coaching process. Postulating a primary importance of the relationship, they offer a different conceptualization to the above by Cox et al (2014a). Others see coaching as a discursive process (Western, 2012) or as a meaning-making process (Stelter, 2014), which could also be explored if a more granular analysis of a coaching session were undertaken.

Empirical research investigating the coaching process has increased in recent years. For this review we divide these studies into three different groups depending on the focus of their investigation. The first group of studies aims to test theories (hypothesis testing studies). Much of this research has set out to identify the relationship between a small number of variables and coaching outcomes (Myers, 2017). Ianiro, Lehmann-Willenbrock, and, Kauffeld (2015) for example explored affiliation and dominance patterns in coaching sessions. While these and similar studies (Myers, 2017) provide useful insights into the coaching process, they overlook the overall characteristics of coaching sessions. Moreover, most studies investigating the impact of key variables in influencing coaching outcomes have tended to explore the effects of inputs into the coaching process rather than the interaction itself. The coaching relationship has been explored and the literature relating to this factor is growing (de Haan \& Gannon, 2017). However, the coaching relationship is only part of the coach-client interaction. 
It could even be argued that the relationship is an outcome of the coach-client interaction rather than being part of the coaching process itself (Myers, 2017).

A second group of studies exploring coaching process addresses only specific events during the coaching process. The Ashridge Critical-Moment Study Group (de Haan \& NieB, 2012) for example has carried out an extensive programme of research investigating the nature and frequency of a 'critical moment,' defined in terms of "an exciting, tense or significant moment' (de Haan, 2008, p.92) experienced during coaching sessions. The exploration and classification of critical moments provides valuable insight into the coaching process, including drawing distinctions between "run-of-the-mill coaching and...dramatic moments and ruptures" (de Haan Bertie, Day, \& Sills, 2010, p.125). The research suggests that most everyday coaching is a process through which "coaches need to help clients look beyond their current solutions and mindset...Epiphanies are not necessarily what is needed. Sometimes, creating a sense of support and reflection is adequate" (de Haan et al., 2010, p.125). This finding suggests that most everyday coaching has a pragmatic sense of working collaboratively with the client to help the client achieve insights without intentionally being deeply explorative or transformative.

Another useful finding from the work of de Haan and associates is in how their research suggests broad agreement in the recall of critical moments between coaches and clients. This has led de Haan et al. (2010) to refute the "Rashomon" experience identified in psychotherapy research (Mintz, Auerbach, Luborsky, \& Johnson, 1973; Weiss, Rabinowitz, \& Spiro, 1996) in which client, practitioner and/or observer tend to recall different accounts of the same session. (The allusion to the 'Rashomon experience' is based on a film by Akira Kurosawa, 1950, in which 4 characters recount the same event in very different ways). However, the findings in a subsequent study involving sponsors of coaching as well as coaches and clients were less clearcut (de Haan \& NieB, 2015). While deeply informative of coaching practice, research on 
critical moments risks presenting coaching as a series of significant moments rather than a continuous interaction and doesn't characterize the overall patterns of coaching.

A third group of studies investigating coaching process is the smallest group of studies, but most relevant for our investigation. These studies attempt to consider the coaching assignment as a whole and aim to classify different types of coaching. Stein (2009), for example, has analysed coaching practice in terms of sixteen conversational identities (e.g., agenda facilitator, action facilitator, problem solver) coaches might adopt within three task frames when coaching (attention to the content of the discussion, the process or management of the content and the relationship). This is an important study, but it focuses on coach behaviours rather than a broader range of characteristics of coaching sessions.

From a theoretical perspective, Segers, Vloeberghs, Hendrickx, \& Inceoglu (2011) classify coaching traditions drawing on a model derived from psychotherapy research (e.g., L'Abate, Frey, \& Wagner,1982) in terms of emotionality (humanistic), rationality (e.g., cognitive behavioural and psychodynamic), activity (e.g., behaviourist), awareness-raising (e.g., Gestalt) and context schools. Each school is characterized by a range of specific interventions. For example, in the 'Emotionality school', the coach draws on techniques such as restatement, paraphrasing, listening, reflecting on feelings, summarizing and focuses on the phenomenological experience and feelings of the client. The 'Rationality' school focuses on cognitive processes and may include techniques such as working with transference processes and resistance. The 'Activity' school stresses rewards and reinforcers as well as modelling. The 'Awareness' school includes a Gestalt approach which typically draws on "experiments." The 'Context' approach is systems oriented. Segers et al. (2011) highlight how there is much overlap across the different schools, which further illustrates the challenge in marking clear distinctions across coaching practices. Segers et al. (2011, p. 207) state that a major problem in understanding these approaches and their differences is a lack of empirical validation. Their 
model, based on combining the who (who provides the coaching), the what (the type of coaching relating to the level of engagement required) and the how of coaching (the different traditions) leads to a possible 60 combinations of approaches. They suggest the existence of 13 likely combinations which still renders the task of identifying what might be understood as the core characteristics of coaching very difficult.

Culpin, \& Curd (2011) conducted research asking clients to provide feedback on their coaching experiences using a behavioural questionnaire (de Haan \& Burger, 2004). The questionnaire is based on Heron's (1976) range of interventions used in a wide range of helping interventions and is intended to identify coaching styles. The styles are Directing (giving advice, making suggestions and recommendations); Informing (providing information and knowledge; summarizing); Challenging (providing feedback to increase self- awareness and to explore assumptions); Discovering (increasing insight by encouraging self-exploration); Supporting (promoting self-confidence/esteem and Releasing (exploring emotions which may be blocking progress). The styles are useful but don't take appear to take account of the context in which these styles might usefully be applied or how they are applied (e.g., with more, or less tact). The relevance of challenge and support, two of the behaviours assessed in the questionnaire has been highlighted elsewhere in the literature with Blakey and Day (2012) arguing that coaches often overlook the need to be more challenging.

Bachkirova et al. (2015) developed an instrument (the Coaching Process Q-Set; CPQS) that would allow for the detailed interactive process between coach and client to be analysed systematically at the level of a whole session. Coaches worldwide were asked to use the instrument to describe a typical session. Their descriptions led to a conceptualization of coaching in which the role of the coach is to "explore and understand the worldview and goals of the client...The session is a fluid process with an atmosphere of warmth...The role of the coach could be best conceptualized as a "collaborative explorer"” (p.448). This study 
suggested that there was widespread consensus about how coaching is practiced. While an important and useful step in coaching process research, the study did not analyse actual coaching sessions. However, the study did provide a methodology for exploring coaching session in-depth and is used in this investigation.

The concepts and theories described above provide useful ideas for how coaching can be conceptualized as an overall process that leads to changes that people make in their lives. These propositions have only been partially tested (e.g., the quality of relationships as a factor) and need more fine-tuned analysis according to different types of coaching. The empirical studies, on the other hand, provide a wealth of data that is difficult to compare considering differences in how coaching is conceptualized and conducted. A typology of coaching that is based on empirical data from the perception of real coaching sessions may be able to provide useful distinctions in the evaluation of research findings and conceptualization of coaching process that is more meaningful for coaching practitioners. With such an intention this study is designed to analyse 6 real-life coaching sessions involving 47 participants: experienced coaches and their clients in action and coaches observing coaching sessions.

Many coaching process investigations adopt the dominant positivist approach to analysing coaching process using what might be described as "hypothesis testing" studies and which typically attempt to predict outcome from a small number of variables (Myers, 2017, p.596). A similar approach has been adopted in psychotherapy. Hardy and Llewelyn (2015, p.187) have argued that what "is striking about this approach is that despite many thousands of studies, few variables have been found to consistently predict outcome across most studies". The authors cite as notable exceptions, the quality of the relationship and the client's commitment (p. 187). Hardy and Llewelyn (2015) list many reasons for the limitation of findings in process research including "small and unrepresentative samples" (p.190). Similar criticisms have been made elsewhere in the literature on psychotherapy process including 
Elliott (2010) who highlights how some limitations could be addressed, including the use of large sample sizes, citing an example of a study which involved over 1000 participants. It is highly unlikely however that coaching process researchers will readily be able to involve over 1000 coaching clients experiencing a similar type of coaching engagement given that coaching is usually provided only for small numbers of executives in very specific contexts. Even if such research was possible, the review provided by Hardy and Llewelyn (2015) and other studies (e.g., Elliot, 2010) suggests that it is unclear if hypothesis testing approaches in coaching are likely to lead to the identification of causal links between process variables and outcomes. A more useful research approach might be to employ research methods which adopt a different paradigmatic conceptualisation of the research process and this is what $\mathrm{Q}$ methodology achieves. Watts and Stenner (2005, p.69) describe how Q methodology "was designed for the very purpose of challenging the dated Newtonian logic of 'testing' that predominates in psychology. Q methodology "is most often deployed in order to explore (and to make sense of) highly complex and socially contested concepts and subject matters from the point of view of the group of individuals involved" (Watts and Stenner, 2005, p.70).

\section{Methods}

The study is designed according to Q methodology (Watts \& Stenner, 2012) using the Coaching Process Q Set (CPQS; Bachkirova et al., 2015), a specially designed tool for analysing whole coaching sessions. The purpose of the CPQS is to identify how coaches, clients and observers describe coaching sessions; that is to identify individual and collective viewpoints about sessions they have taken part in or observed, and which may indicate a potential typology of coaching. The instrument consists of a "comprehensive generic set of [80] descriptors" (Bachkirova et al., 2015, p.435) of typical mid-engagement coaching sessions 
including coach and client behaviours and other defining session characteristics (e.g., "Coach shows empathy" and "There is a sense of optimism in the session").

These descriptors ( $Q$ items) are typically written on playing sized cards (one Q item per card). Clients, coaches or observers of coaching sessions are asked to rank-order the cards in an ordinal scale according to how "characteristic/uncharacteristic" the Q items appear to describe a coaching session from their point of view. This leads to relative subjective judgements; for example, that the "Coach shows empathy" more than "There is a sense of optimism in the session”. In sorting the Q items, coach, client and/or observers are presented with a template made up of a fixed number of columns and rows with directional arrows asking participants to place the Q items according to how "characteristic" or "uncharacteristic" they appear to describe the session in focus. In this study, a 13-point scale was used (-6 through to 0 through to +6 ), consistent with scaling decisions for $Q$ sets (the total set of Q items) of this size (Brown, 1980). The number of Q items (rows) to be ranked in each column is illustrated in Figure 1. Each completed rank-ordering of $\mathrm{Q}$ items is called a $Q$ sort.

There is some debate in the literature as to whether participants might use free or nonstandardized distributions (Watts and Stenner, 2012, p.78). For example, participants might well wish to position Q items differently to a distribution pattern which only allows participants to position fixed numbers of Q items on a scale as is the case in the CPQS. However, Block (2008, p.45) strongly argues against this and includes in his argument that “idiosyncratic Q-distribution shapes are inconsequential in their effect."

If a Q item is placed towards the "highly characteristic" end of the distribution, then the viewpoint being expressed is that that $\mathrm{Q}$ item describes a key characteristic of the session. Similarly, if a Q item is placed towards the "highly uncharacteristic" end of the distribution, then the viewpoint being expressed is that that $\mathrm{Q}$ item describes what the session was not like. Q items that are positioned towards the middle of the distribution are considered neither 
particularly characteristic nor uncharacteristic of the session (neutral); they are not defining characteristics. Since the Q items are given numerical values for each participant, it is possible to intercorrelate whole Q sorts; that is to compare the Q sort of the coaches with those of the clients and observers. Factors are extracted through what is described in Q methodology as a by person factor analysis (Brown, 1980). The factors identify common variance (similar ways of rating the Q items in the inter-correlated Q sorts). Each factor therefore represents a shared viewpoint. Typical factor analytical procedures are conducted including factor rotation. Participants whose Q sort loads significantly onto a given factor are considered to share a common viewpoint in describing a session.

A factor array is created for each extracted factor. It is a "single Q sort configured to represent the viewpoint of a particular factor" (Watts \& Stenner, 2012, p.140). It is configured in the same sorting pattern used to sort the data ( -6 to +6 with the same number of rows) and derived from the $\mathrm{Z}$ scores of the $\mathrm{Q}$ items which load onto each factor identified in the study.

The final and most important step in Q methodology and in the use of the CPQS is to describe the viewpoint expressed in each factor array. This should be done by reviewing the overall configuration of Q items in each factor array as a Gestalt of Q items (Watts \& Stenner, 2005, p.70). Those Q items which are at the ends of the distribution (rated as highly characteristic or highly uncharacteristic) are considered particularly important because they describe psychologically salient characteristics of how the session appears. Typically, the factors are identified for all participants collectively. It is then possible to identify those participants whose Q sorts load onto the factors and to compare differences in descriptions expressed in the factor arrays. The description of each factor array is presented as a written narrative referring to the position of Q-items. Q methodology has been described as "qualiquantological" (Stenner \& Stainton Rogers, 1995) to illustrate how quantitative techniques are used in qualitatively oriented research. 


\section{Less Characteristic of Session}

More Characteristic of Session

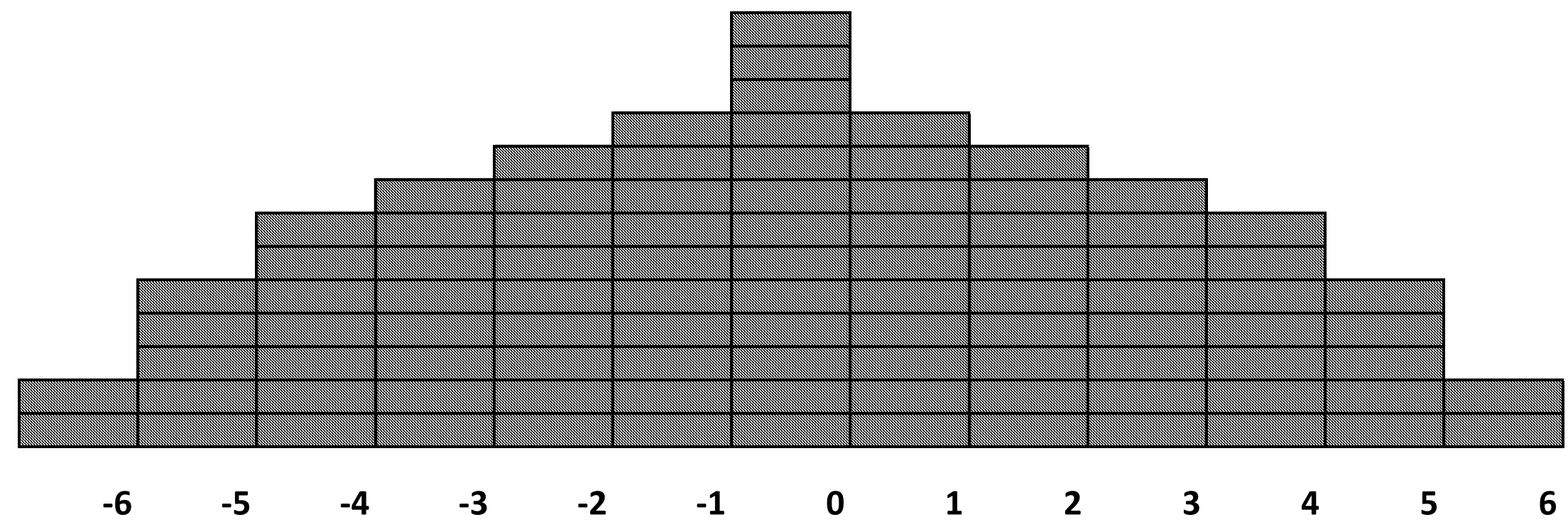

The coach, coachee or observer positions each $Q$ item (session descriptor) to the left or right of the distribution according to how characteristic the $Q$ item is considered to represent the session. $Q$ items placed more to the right of the distribution are increasingly characteristic of the session. $Q$ items placed to the left are increasingly less characteristic of the session. There are fixed numbers of $Q$ items that can be placed in any column as showing in the diagram 


\section{Participants and data collection}

Six coaches were invited to hold a coaching session, each with a different client (all holding senior managerial responsibilities) using snowball and self-selection sampling (Saunders, Lewis, \& Thornhill, 2015). All coaches conducting coaching sessions were highly experienced with a typical 20 years or more of workplace coaching as the main source of income) and based in the UK but with some including in their practice international assignments. While most of these coaches referred to a generally humanistic approach to their coaching practice, there were some important differences in how these coaches conducted their sessions. The coach for Session 1 said that he drew on a range of approaches and in his own idiosyncratic model emphasised a focus on the client's use of language and his own role in helping the client to identify patterns. Session 1 was very much aligned with how he typically practised. The coach for Session 2 described her approach as more eclectic, typically drawing on psychometrics, cognitive-behavioural methods and Neuro-Linguistic Programming. The coach described her recorded session more in existential terms in how she focused on the client to discover what valued to him in life and to make choices based on those values. The Coach for Session 3 described how she drew primarily on her sense of intuition. The main focus of the recorded session was based on a visualization exercise involving a time-line. The Coach for Session 4 described her session very much in terms of a strongly grounded Gestalt orientation. Her session focused on a discussion of how the client might be able to integrate two alternative constructions of self and featured an empty-chair exercise. The Session 5 coach described her approach as a process of "coaching and consultation" in which she would draw on her professional business background to help the client find answers to the challenges the coach faced. She described her approach as being very "anti-psychologising." This way of facilitating the coaching process was demonstrated in how she gave practical suggestions to the client about how to network more effectively and deliver business presentations. The coach for 
Session 6 described her approach in person-cantered terms and this was evidenced in the way that she stayed closely with the client's own frame of reference, demonstration of empathic listening and strong relationship building.

All coaches were working primarily at senior levels in organizations. 'Experienced coaches' (3 years or more of experience) were invited to take part as observers and were also identified using snowball and self-selection sampling. In practice, the experience of the coaches taking part varied with some highly experienced coaches and others who appeared to be developing their practice (e.g., 4 observers were identified as MA students); formal coach training also varied and with some coaches describing strong preferences for specific coaching approaches (e.., 'Gestalt', 'solutions-focused') and others more 'eclectic'. While the observer sample was not strictly a random sample of coaches, the mix of the observer groups was indicative of a diversity of coaches practising coaching in the UK.

A professional video-recording was made of all 6 sessions (60-90 minutes each). Q sorting typically followed immediately after the sessions or within 48 hours of the sessions. The coaches invited to take part as observers viewed the recordings in groups of 4-8 and with each observer viewing only one of the six sessions. None of the coaches acting as observers had any personal knowledge of the coaches or clients. Some limited introduction to the sessions was provided (e.g., if it would be a "one-off session" or "the last session in a series of sessions") but this information was kept to a minimum to avoid influencing how the observers might have interpreted the sessions. After collecting the Q sorts from participants, all participants were given an opportunity to comment on the sessions (there had been no discussion of the sessions until after Q sorts had been completed individually). Normally in Q methodology, these comments are only used to help clarify or confirm viewpoints expressed in factor arrays rather than analysed separately using other qualitative methods. 


\section{Results}

Two factors (F1, F2) were extracted and rotated (varimax) using PQ Method (Schmolck, 2014). The factors were then manually rotated 12 degrees (anticlockwise) to position the individual Q sorts either side of the two factors. This is a recommended practice in Q methodology (Brown, 1980). Through manual rotation, the two factors are positioned to provide a central viewpoint through the middle of those participants loading significantly onto those factors. Figure 2 shows the rotated factors and the positions of the 46 participants loading onto the two factors (all participants completed Q sorts excepting the client for session 6). Table 1 presents the same data allowing the identification of the participants in Figure 2. All loadings greater than 0.28 are significant at $\mathrm{p}<0.01$ and all $\mathrm{Q}$ sorts load significantly on at least one factor. The study explained $32 \%$ of the study variance. The validity of both factors is confirmed given that both have acceptable eigenvalues loading >1 (Watts \& Stenner, 2012; Factor 1:10.3; Factor 2: 4.4).

Twenty-Five Q sorts (54\%) loaded significantly onto only factor 1 (Group 1: Figure 2). These comprised 12 observers of Sessions 1 and 2; 4/5 clients completing Q sorts, 4/6 coaches and 5 observers from a range of other sessions. Nine Q sorts (20\%) loaded significantly onto only factor 2 (Group 2). These were 3/4 of the observers for Session 3; 1/8 of the observers for Session 4; 4/6 of the observers for Session 5 and 1/4 of the observers for Session 6. Finally, 12 Q sorts (26\%) loaded significantly onto both factors 1 and 2 (Group 3). These included the coaches for Sessions 1 and 3, the client for session 3 (inverse loading on Factor 2 but her prime loading was still on factor 1 and is included in Group 1 as she was the only participant loading significantly at the reverse polarity of factor 2) and a mix of observers from across sessions 3-

6. There were no instances of significant loadings at the opposite pole of Factor 1. 
Figure 2: Factor Loadings for All Participants and All Sessions

Factor 1 Viewpoint (+)

Group1: Sessions 1 \& 2 observers, coaches and coachees

Group 3: Sessions 4 and 6 observers

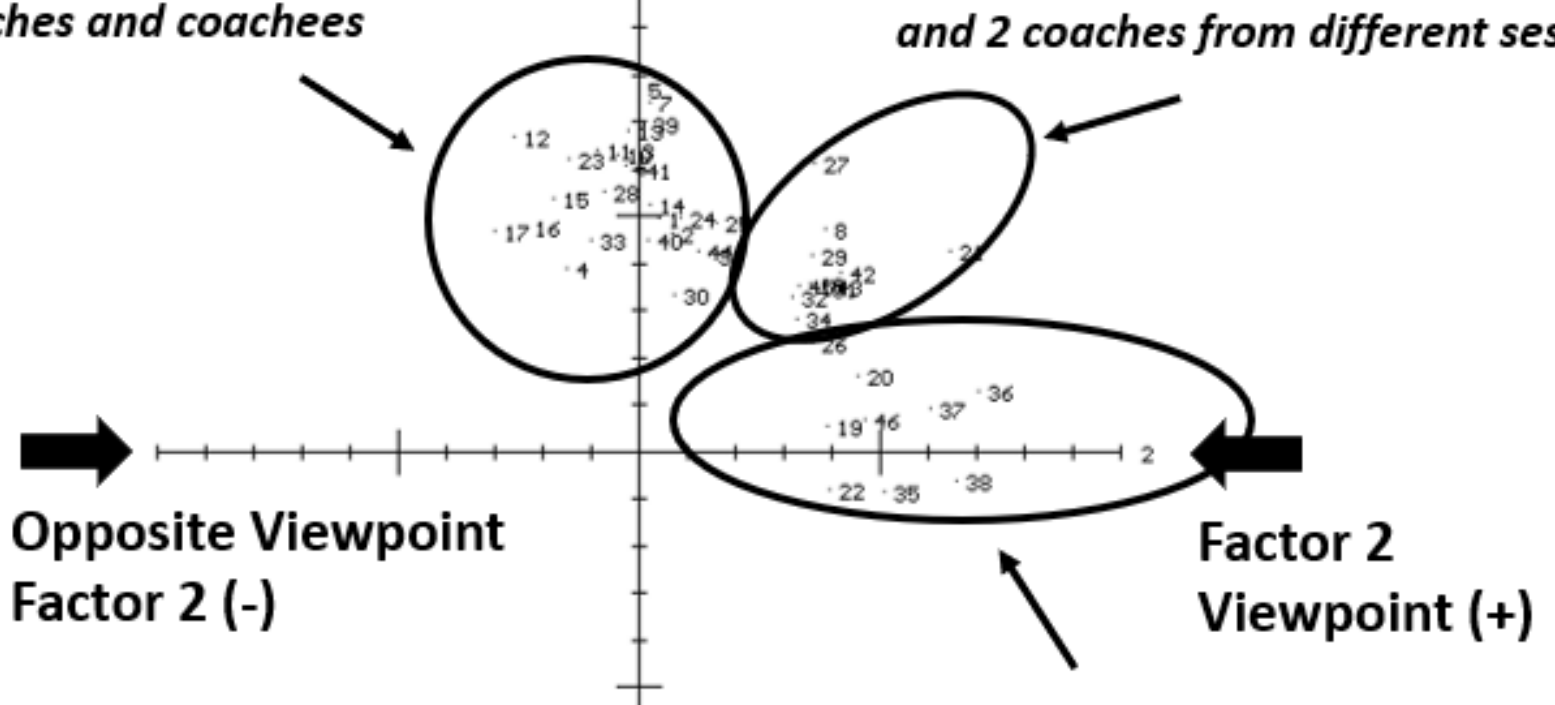

Group 2: Sessions 3 and 5 most observers

Opposite

Viewpoint Factor 1 (-) 
Table 1:

Loadings for Each Participant by Session

\begin{tabular}{|c|c|c|c|c|c|c|c|}
\hline & No. & FACTOR 1 & FACTOR 2 & NO & No. & FACTOR 1 & FACTOR 2 \\
\hline SESSION 1 & & & & SESSION 4 & & & \\
\hline CLIENT & 7 & $0.74^{*}$ & 0.03 & CLIENT & 23 & $0.62^{*}$ & 0.14 \\
\hline $\mathrm{COACH}$ & 8 & $0.47^{*}$ & $0.39 *$ & $\mathrm{COACH}$ & 24 & $0.50^{*}$ & 0.09 \\
\hline Observer 1 & 1 & $0.50 *$ & 0.04 & Observer 1 & 25 & $0.49 *$ & 0.16 \\
\hline Observer 2 & 2 & $0.46^{*}$ & 0.07 & Observer 2 & 26 & 0.23 & $0.36 *$ \\
\hline Observer 3 & 3 & $0.64 *$ & 0.02 & Observer 3 & 27 & $0.61 *$ & $0.36 *$ \\
\hline Observer 4 & 4 & $0.39 *$ & -0.15 & Observer 4 & 28 & $0.55 *$ & -0.07 \\
\hline Observer 5 & 5 & $0.77^{*}$ & 0.01 & Observer 5 & 29 & $0.42^{*}$ & $0.35^{*}$ \\
\hline Observer 6 & 6 & $0.61 *$ & 0.03 & Observer 6 & 30 & $0.33^{*}$ & 0.07 \\
\hline Observer 7 & $N / A$ & $N / A$ & $N / A$ & Observer 7 & 31 & $0.35^{*}$ & $0.38^{*}$ \\
\hline Observer 8 & $N / A$ & $N / A$ & $N / A$ & Observer 8 & 32 & $0.33 *$ & $0.32 *$ \\
\hline SESSION 2 & & & & SESSION 5 & & & \\
\hline CLIENT & 10 & $0.63 *$ & -0.05 & CLIENT & 39 & $0.70^{*}$ & 0.01 \\
\hline $\mathrm{COACH}$ & 9 & $0.42 *$ & 0.15 & $\mathrm{COACH}$ & 40 & $0.45^{*}$ & 0.02 \\
\hline Observer 1 & 11 & $0.64 *$ & -0.09 & Observer 1 & 33 & $0.45 *$ & -0.10 \\
\hline Observer 2 & 12 & $0.67^{*}$ & -0.26 & Observer 2 & 34 & $0.28 *$ & $0.32 *$ \\
\hline Observer 3 & 13 & $0.69 *$ & -0.02 & Observer 3 & 35 & -0.09 & $0.51 *$ \\
\hline Observer 4 & 14 & $0.53 *$ & 0.02 & Observer 4 & 36 & 0.13 & $0.71 *$ \\
\hline Observer 5 & 15 & $0.54^{*}$ & 0.18 & Observer 5 & 37 & 0.09 & $0.61 *$ \\
\hline Observer 6 & 16 & $0.48^{*}$ & -0.24 & Observer 6 & 38 & -0.06 & $0.66^{*}$ \\
\hline SESSION 3 & & & & SESSION 6 & & & \\
\hline CLIENT & 17 & $0.47^{*}$ & $-0.30^{*}$ & CLIENT & & $N / A$ & $N / A$ \\
\hline $\mathrm{COACH}$ & 18 & $0.36^{*}$ & $0.36^{*}$ & $\mathrm{COACH}$ & 41 & $0.60^{*}$ & 0.00 \\
\hline Observer 1 & 19 & 0.06 & $0.40^{*}$ & Observer 1 & 42 & $0.38 *$ & $0.42 *$ \\
\hline Observer 2 & 20 & 0.16 & $0.45^{*}$ & Observer 2 & 43 & $0.36^{*}$ & $0.39 *$ \\
\hline Observer 3 & 21 & $0.43^{*}$ & $0.65^{*}$ & Observer 3 & 44 & $0.43^{*}$ & 0.12 \\
\hline Observer 4 & 22 & -0.08 & $0.40^{*}$ & Observer 4 & 45 & $0.35 *$ & $0.33^{*}$ \\
\hline Observer 5 & $N / A$ & $N / A$ & $N / A$ & Observer 5 & 46 & 0.07 & $0.47^{*}$ \\
\hline
\end{tabular}

*Denotes a significant loading: $p>0.28 p<0.01$ 
The identification of three groups of participants aligning either onto factor 1 , factor 2 or a mix of factors suggests two clearly differentiated descriptions of coaching sessions: factor 1 (primarily observers of sessions 1 and 2, clients and coaches) and factor 2 (primarily observers of sessions 3 and 5). The third grouping is a mix of these descriptions (primarily observers of sessions 4 and 6, secondary loadings of two coaches and the session 3 client, inverse loading). In summary, the clients always tended to describe (in their Q sorts) the sessions which aligned with factor 1 and in one case tending toward a viewpoint that was diametrically opposed to factor 2 . The perspective of the observers was more mixed and varied according to the session observed. The coaches generally aligned with the perspective of the clients but could be more nuanced. The factor arrays for Factors 1 and 2 are provided in Table

2. For ease of reference, they are shown side by side with factor scores for each so that similarities in the ranking of each Q item in the respective factor arrays can be identified.

TABLE 2

\section{FACTOR ARRAYS (F1: “Client-led Coaching” \& F2: "Process-Led Coaching”)}

\begin{tabular}{llll}
\hline No & F1 & F2
\end{tabular}

1 There is an exploration of the effect of client's choice of words $\quad \begin{array}{ll}1 & -3\end{array}$

2 There is an exploration of the client's values $\quad 0 \quad-5$

3 There is an exploration of the client's environmental influences (e.g., $\begin{array}{lll}0 & -2\end{array}$ organization, family, politics, history)

4 There is an exploration of the client's underlying mindset (e.g., $\quad 2 \quad-6$ assumptions, beliefs, stories)

5 Coach and client explore the deeper meaning of a presenting issue $\quad+1 \quad-6$

6 Coach works with the clients' apparent defensiveness $\quad-1 \quad-4$

7 Coach points out recurrent theme in client's behaviour $3 \quad \begin{array}{ll}3 & 0\end{array}$

8 Coach points out potential unconscious motives of the client (out of the $\begin{array}{lll}0 & -5\end{array}$ client's awareness)

9 There is an exploration of the client's in-session non-verbal behaviour $\begin{array}{llll}-1 & 0\end{array}$ 
10 Coach invites client to consider other people's perspectives on an issue $\begin{array}{lll}0 & -1\end{array}$

11 Coach invites client to identify resources and how they might be $\quad+2 \quad+2$ leveraged (including strengths, accomplishments and/or external resources)

12 Coach highlights client's resources (including strengths, $+1 \quad 0$ accomplishments and/or external resources) and how they might be leveraged

13 Coach explores client's emotions

14 Coach encourages client to feel more deeply within session $+1 \quad-4$

15 Coach encourages client to become more aware of his immediate $0 \quad-5$ experience in the session

16 Coach challenges client's perspective of situation and or self

17 Coach asks client to quantify feeling/ perception/ issue using a scale

18 There is one or more, periods of silent reflection $-4 \quad-2$

19 There is a discussion of the results of a psychometric instrument $0 \quad-5$

20 There is a discussion of external feedback $-4 \quad 0$

21 Coach gives feedback from coach's experience of client $1 \begin{array}{ll}1 & -2\end{array}$

22 Coach discloses own feelings/ bodily sensations evoked in the session $\quad-3 \quad-4$

23 Coach describes her perception of the situation $\quad+4 \quad+2$

24 There appears to be a productive use of metaphors $\quad-2 \quad-3$

25 Coach and client explore their differences in perception of the situation $\quad \begin{array}{lll}-2 & -4\end{array}$

26 Coach expands on client's statements $\quad+2 \quad+3$

27 Coach provides reassurance to client $\quad+2 \quad+4$

28 Coach uses humour $\quad \begin{array}{ll}0 & +3\end{array}$

29 Coach shows empathy $+5 \quad+3$

30 Coach shares personal details about herself $\quad-3 \quad 0$

31 Coach repairs lost connection to the client during the session $\quad-4 \quad-1$

32 Coach discloses own fallibility $\quad-3 \quad-3$

33 There appears to be rapport (strong connection) between client and $\quad+6 \quad+1$ coach

34 Coach and client appear to understand each other $\quad+5 \quad+3$

35 Coach and client discuss their relationship $\quad-2 \quad-4$

36 Coach asks for permission to give feedback $\quad-2 \quad-4$ 
37 Coach repeats client's words back to him

38 Coach paraphrases the client's statements

$+2+5$

39 Coach checks if her understanding is correct

$+3+2$

40 There is a sense of optimism in the coaching session

$+3+1$

41 There appears to be a shift in energy during the coaching session

$+2+2$

42 Coach and client appear to be engaged (vs. disengaged)

$+6 \quad+4$

43 Coach and client use development plan to guide sessions

$-4 \quad-1$

44 Coach follows up on key/ significant statements made by client

$+4 \quad 0$

45 Coach asks questions helping the client elaborate

$+5 \quad+2$

46 There is a discussion of the coaching contract

$-2+1$

47 There is a discussion of issues related to the termination coaching

$-2 \quad-1$

48 There is a discussion of boundaries and/ or ethical issues relating to the $-4 \quad-1$ coaching engagement

49 There is a discussion of a potential referral to an outside specialist (e.g., therapist, doctor, financial advisor)

50 The session is fast-paced

51 The session appears highly structured

52 Coach and client appear to bring the session to closure easily

53 Coach and client discuss the process of the session

54 Coach takes an active role during the session

55 Coach makes explicit a shift in role during the session (e.g., acting as

$-1 \quad 0$
consultant, teacher, therapist)

56 Coach explains the reason behind using a specific intervention

57 Coach appears to be using an intervention mechanistically

58 Coach appears to be pursuing her own agenda

59 Client takes initiative in structuring the session

60 There is a discussion of client's feedback on coaching

61 Coach makes sounds or non-verbally encourages client to continue

62 Coach is verbose

63 Coach interrupts client

64 Client interrupts coach

65 Coach suggests in-session exercise/ activity

66 Coach broadens the focus of discussions 
67 Coach asks questions that appear to open new possibilities for the $\quad+3 \quad 0$ client

68 Coach appears to focus on a third party's agenda (e.g., organization, $\quad-3 \quad-1$ line manager)

69 Clients suggest his next course of action $\quad+1 \quad+1$

70 There is discussion of new practices for the client $\quad+4 \quad+1$

71 Coach offers possible solutions $\quad+2 \quad+4$

72 Coach suggests homework forlclient $\quad-1 \quad+1$

73 Coach shares her knowledge about topic $\quad-0 \quad+1$

74 Coach gives advice $\quad \begin{array}{ll}0 & +3\end{array}$

75 Coach follows up on previous homework $\quad-1 \quad-1$

76 Coach encourages client to make choices $\quad+3 \quad+2$

77 Coach asks the client to describe key learnings/ takeaways from $\quad+3 \quad+3$ session

78 There is a discussion of the client's progress $\quad+1 \quad+2$

79 There is a discussion about the client's overall goals $\quad+1 \quad+4$

80 There is a discussion about how to measure the success of the coaching $-3 \quad-2$ engagement

81 Coach redirects client to client's agenda $\quad-1 \quad+1$

82 Coach explores client's level of engagement in coaching $-6 \quad-3$

83 Coach enquires about client's aim for the session $\quad+4 \quad+5$

84 There is a discussion of the client's impact on his environment (e.g., $\quad \begin{array}{lll}0 & -3\end{array}$ organization/family)

Notes: 1) the numerical values in the columns for F1 and F2 indicate the positioning of the Qitems in the Factor Arrays. For example in Factor 1, Q33 and Q42 are positioned at the far right of the distribution (+6) meaning that these were the $Q$ items that were most typically rated as highly characteristic of the session experienced or viewed for those participants loading onto F1. Conversely, Q57 and Q82 are positioned at -6 indicating how participants loading onto F1 considered these $Q$ items to be highly uncharacteristic of their description of the coaching sessions they experienced or viewed 
2) the version of the CPQS used was a prototype of the version published in Bachkirova, Sibley and Myers (2015). Q23, Q31\& Q43 were considered redundant \& removed in the final version; $Q 11$ and $Q 12$ were combined. These changes are not considered to impact on the content validity of the $Q$ sort.

\section{Factor 1: "Client-led coaching"}

The Factor is described as "Client-led coaching" to reflect a clear focus on the client. The session is explorative and relational but without being deeply emotional, psychologically challenging or transformative. The derivation of this description is based on an interpretation of the configuration of Q items expressed in the factor array. Consistent with typical studies in Q methodology (Watts and Stenner, 2005), the derivation of this factor is now explained in relation to the configuration.

Those Q items with the highest positive loadings on Factor 1 relate to rapport $(33:+6)$, empathy $(29:+5)$ and understanding $(34:+5)$. There is strong engagement $(42:+6)$. The coach is active (Q54: +4) asking lots of questions $(\mathrm{Q} 45:+4)$, picking up on significant statements $(\mathrm{Q} 44:+5)$ and making restatements $(\mathrm{Q} 37:+4)$. The coach describes her perception of the situation $(\mathrm{Q} 23:+4)$ and is attentive to the purpose of the session $(\mathrm{Q} 83:+4)$ rather than allowing the conversation to take its own direction. The coach is listening (Q61: +5; Q39: +3). This further indicates attentiveness to the client. There is limited exploration of the client's mindset $(\mathrm{Q} 4:+2)$ or of the deeper meaning of a presenting issue $(\mathrm{Q} 5:+1)$ but the client is challenged to consider their perspective on self and events $(\mathrm{Q} 16:+4)$. There is little discussion of the unconscious (Q8: 0), defensiveness (Q6: -1), values (Q2: 0), emotions (Q13: 1), in-session behaviour (Q9: -1) or experience in the session (Q18: 0). There aren't lots of silences (Q:18: 0) 
for the client to reflect. There isn't a sense of transformation in the session with only some shift in energy $(\mathrm{Q} 41:+2)$ although some new possibilities are identified $(\mathrm{Q} 67:+3)$. Those Q items with the highest negative loadings suggest a fluent approach (i.e. not mechanistic: Q57: -6; nor structured: Q51: -5). The pace is comfortable (i.e., not fast paced: Q50: -4) and is not characterized by mechanistic interventions such as psychometric instruments (Q19: -4$)$ or development plans (Q43: -4). The coach is very much focused on the client agenda (Q 58: -5) and does not dominate the conversation (i.e. is not verbose: Q62: -5). The coach holds the client accountable by encouraging the client to make choices $(\mathrm{Q} 76:+3)$. The session has a practical orientation with an emphasis on new practices $(Q 70:+5)$ and a generally optimistic atmosphere (Q40: +3).

\section{Factor 2: "Process-led Coaching"}

The factor is described as "Process-led coaching" to convey a sense of the coach orchestrating a structured coaching process with the use of interpersonal skills, techniques and activities. Process dominates rather than relationship or exploration of the client or client's concerns. The derivation of this factor now follows.

The factor array for F2 is characterized by a complete absence of depth and breadth of exploration and this is indicated most clearly in the high factor loadings in a negative sense (the opposite meaning of the Q item descriptors). The described session was not perceived to explore deeper meanings (Q5: -6) or the mindset of the client (Q4: -6). There is no exploration of values (Q2: -5), unconscious motives (Q8: -5), defences (Q6: -4), emotions (Q13: -4), feelings (Q14: -5) or of the coaching relationship (Q35: -4). There is no space for reflection (Q18: -5). The coach is not permission seeking (Q36: -4), is very active (Q54: +6) dominating the conversation $(\mathrm{Q} 62:+5)$ and expanding on the client's statements $(\mathrm{Q} 38:+5)$. The session is characterized by activity $(\mathrm{Q} 65:+4)$ : the coach is active in giving emotional support in the form 
of reassurance (Q27: +4), showing empathy $(\mathrm{Q} 29:+3)$, offering solutions $(\mathrm{Q} 71:+4)$ and in giving advice $(\mathrm{Q} 74:+3)$. There is therefore a sense of the coach working hard. The coach is active in using a range of questioning and listening skills (Q61: +6; Q38: +5, Q37: +5) so much so that the use of these techniques dominates the appearance of the session. There is a sense of a structured and goal focused process with the aims of coaching being identified $(Q 83:+4)$, a focus on goals specifically (Q79: +4), the session being brought to closure (Q52: +4$)$ and learning being highlighted (Q77: +3). The atmosphere is not intense with ample humour (28: $+3)$ and strong engagement (Q42: +4$)$.

\section{Supporting comments}

The clients all spoke very highly of the coaches and found the sessions very useful. Skills included being "very, very insightful" (client session 2) and "knowing when to ask the killer question" (client session 3). All the clients reported a sense of being challenged but not excessively: “It was kind of challenging without being really challenging. I wasn't being asked for hard and fast solutions" (client session 5). The learning and experience was considered useful ("Just what I needed"; client session 3) but at the same time "there was nothing earth shattering" (client, session 5). There was a sense of the session being focused on them: "She did the right thing: go where I wanted to go" (client session 3). These and similar comments support their descriptions (Q sorts) of their sessions as Client-led coaching: explorative, interactive and client-focused but not excessively challenging. There were no clear evaluative differences in how the clients spoke about any of the sessions, supporting a consensual view about their reported experience.

The coaches all said that the sessions generally represented how they typically coached and their comments were generally consistent with those of the clients supporting their loading primarily onto Client-led Coaching. The coach in session 1 did say that she found herself 
directing the client (giving advice), something she did not normally do which helps explain her loading significantly onto factor 2 as well as factor 1 .

The observers tended to identify the style of the coach as being much more directive in some of the sessions (3 and 5) than the clients had described. One observer (session 4) loading onto factor 2 referred to the "directedness of the coach" while another (session 3) thought that the coach was too "busy in her own head" to be attentive to the needs of the client. The observers of sessions 3 and 5 commented that there was limited breadth or depth of exploration ("lots of missed opportunities"), which was a distinguishing characteristic of factor 2. These comments were made about all sessions but were more pronounced in Sessions 3 and 5. In the case of Sessions 1 and 2, there were many comments which related to the reflective process, characteristic in the factor 1 array. For example, the coach in session 1 was perceived to be "holding a mirror up" to the client but reflection did not equate to in-depth exploration of the client's issues which was considered by many observers to be limited. The observers did highlight the sense of intimacy which is salient in the factor 1 array with one observer commenting that the coach and client even "looked like each other". Overall, therefore, comments made by observers were consistent with the descriptions of factors 1 and 2 . They were also generally critical, particularly when the approach of the coach aligned with Factor 2, suggesting that most observers identified what they considered to be limitations in the approach associated with Factor 2 .

\section{Development of an empirically derived model of coaching practice}

The identification of two factors in this study allows the creation of an empirically derived model describing different types of coaching sessions representing Factors 1 and 2 (Figure 3). Two types were clearly defined (Client-led and Process-led Coaching). A third type of coaching was partially identified which was diametrically opposed to Process-led coaching. 
Only one client loaded onto this inverse polarity of Process-led coaching while also loading onto Client-led coaching, so the factor was not clearly differentiated. However, several Q sorts of other coaches had some (non-significant) loadings onto this polarity suggesting the possibility of this type of coaching. This type of coaching can be conceptualized as radically different to Process-led Coaching. It is described as Dialogic. Another inferred, fourth type of approach, 'Performance Management' is indicated by considering a style of coaching asymmetric to a Client-led Coaching. Figure 3 represents the proposed typology with the following description of each type of coaching.

\section{Figure 3: Empirically Derived Model of Coaching Process}

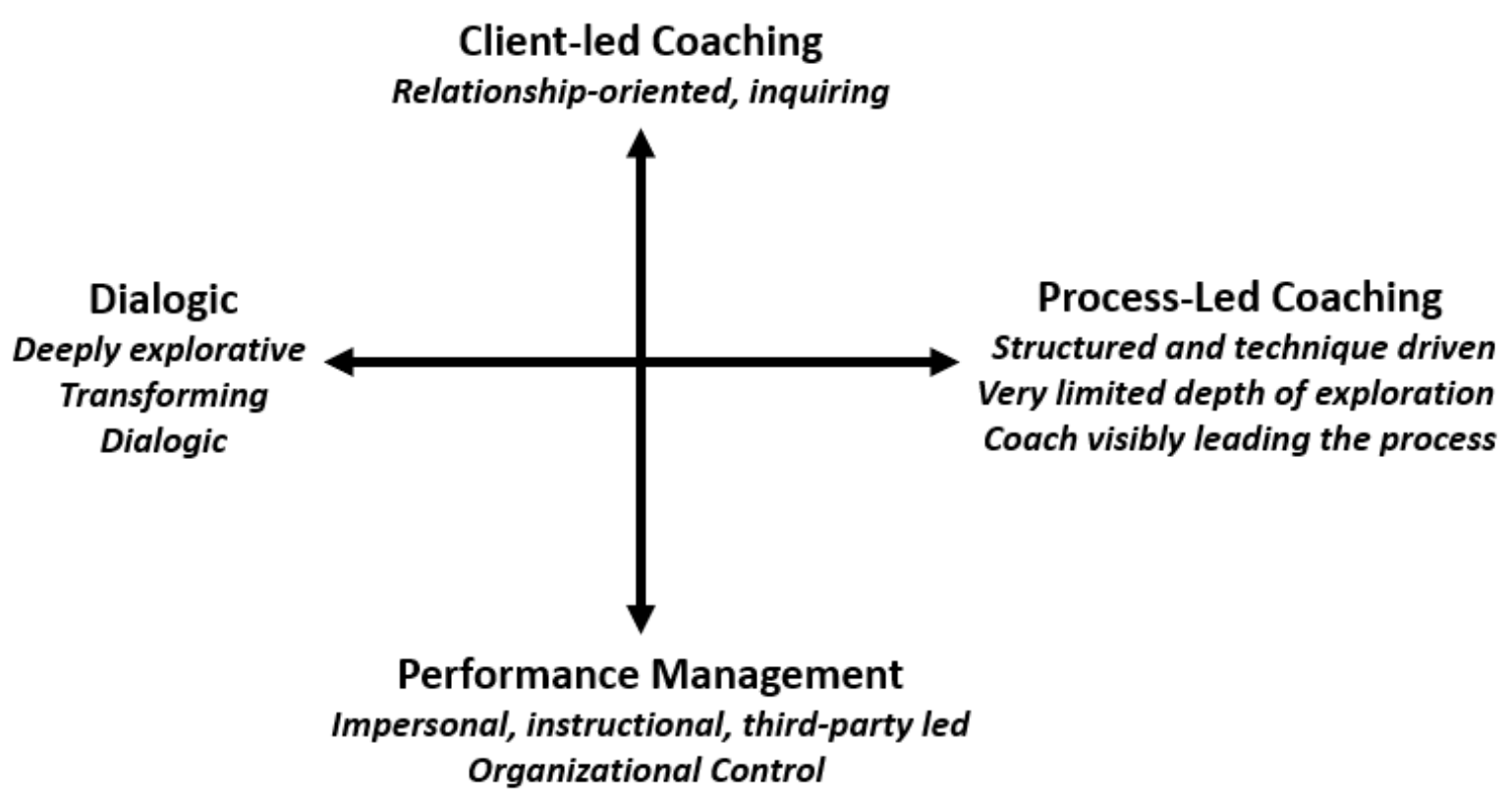

\section{Client-led Coaching}

In this type of coaching, the coach is very attentive to the client, asks lots of questions and gently and lightly explores the client's issues in a non-confrontational manner. There is empathy, rapport and mutual understanding. These aspects of the engagement foreground a trusting and intimate relationship. The session flows in accordance with the needs of the client and there is a focus on practical outcomes rather than an in-depth exploration of the breadth and depth of client issues (e.g., in an overtly psychological exploration of concerns or 
aspirations). There is a sense of collaboration with the coach being active in the conversation and working with the client's frame of reference (e.g., working with the client's aims, being inquiring and curious, picking up on significant statements and encouraging the client to explore further).

\section{'Performance Management'}

In the diametrically opposed approach to Client-led coaching, the practitioner is not attentive to the client's agenda; there is no exploration of issues, no rapport or mutual understanding. Solutions are instructional and prescriptive. There could be formality to the process including use of written reports and the interaction may lead to a referral (e.g., training, extra coaching or disciplinary action). This type of interaction would foreground the interests of a third party (e.g., organization) rather than the client. The approach could be characteristic of serious issues of performance management.

There might be some Q sort descriptors in the CPQS that could begin to correlate at a low level with this type of approach. For example, Q items which would score in a negative sense at this polarity might include the use of a development plan or psychometrics, but the use of these interventions would likely be delivered mechanistically with little checking of understanding or any concern or awareness of how the feedback is being received. The focus would be on how well the person receiving feedback would be meeting organisational norms/ decisions. Another type of interaction that might correlate to some extent with this type might be a manager who has a generally autocratic leadership style, limited sensitivity to others but believing that he or she is expressing a leadership style characteristic of coaching. The notion of 'Performance Management' is intended to stress the nature of performance being managed (led by the organization) rather than common conceptualizations of coaching in which the individual is encouraged to "develop themselves... and is free from the influence or boundaries 
of organizational status structures" (Jones et al., p.205-251). It is not intended to reflect broader and more progressive notions of performance management (e.g., Peterson, 2009)

\section{Process-Led Coaching}

In this type of coaching the coach is directing the process: there is a focus on goal setting, session structure and activity including possibly in-session exercises and the coach appearing to be actively working with a visible use of interpersonal techniques. The relationship is not foregrounded in part because the coach is so engaged in structuring the process that the needs of the client might be overlooked. Similarly, the lack of reflective space, attentiveness to the client's issues and lack of focus on meaning, mindset or client experiencing could be leading to a lack of depth and breadth of exploration.

\section{Dialogic coaching}

A coaching session diametrically opposed to the Process-led coaching involves a depth of exploration including for example, emotions, drives, the coaching relationship, the coaching process, differences in perspectives, values, choice of words, mindset and physical experiencing. However, the explorative process is not visibly directed by the coach and the use of conventional techniques is limited or unnoticeable. The coach is less active in the sense of allowing reflective space rather than talking and is not introducing activities or finding solutions for the client. However, the coach is still involved in the process, encouraging depth of exploration and giving her perspective. The process is more emergent, perhaps with neither the coach nor the client knowing at the outset what the issue might be (there may not be a clear identification of an aim or session goals). There might not be a clear point at which to bring the session to a closure. There may even be moments when the conversation might not appear 
purposeful, leading to a possible disengagement when there might not be a clear understanding between coach and client.

\section{Discussion}

The different types of coaching in the proposed typology resonate with various approaches and style of coaching described in the literature. For example, Client-led coaching is generally aligned with the common description by coaches of their typical approach in the research by Bachkirova et al. (2015). However, the coach of the Client-led type appears less explorative of mindsets than reported by coaches (coaches considered the exploration of mindset as a key characteristic of their practice in Bachkirova et al., 2015) and suggests that coaches might assume they are more exploratory and challenging than they are in practice. Client-led seems to be an approach that emphasizes relationship and is congruent with one of the three frames identified by Stein (2009). It is also associated with (gentle) challenging and supporting styles (Heron, 1976; de Haan \& Burger, 2004).

Process-led coaching seems to relate to a more competency driven approach in which the coaches showed lots of coaching techniques with an awareness of how to actively manage the interaction in a structured manner (e.g., agreeing aims and goals, introducing exercises and activities, making suggestions, bringing the session to closure and capturing learning) but at the expense of a possible lack of depth of exploration or intimacy of relationship. This form of coaching seems consistent with a "directive" style (de Haan \& Burger, 2004). It is a more instrumental approach (Stelter, 2014) and in this sense, might be conceptualized in terms of the coach working from the perspective of the "competent self" (Bachkirova, 2016)

Dialogic Coaching is more associated with an in-depth exploration of the client's way of being (e.g., life purpose, deeper meanings of events) and aspects of self beyond the immediate awareness of client or coach, with parallels to the existential approach in coaching 
(Spinelli \& Horner, 2007). "It is less about developing an immediate shift in specific behaviours and performance than it is about extending clients' understanding of their individual stance in life" (p.126). It is an approach which emphasizes depth of exploration in a manner which is very non-directive. In this sense, it would seem to fit more comfortably with the Humanistic School rather than with the Rationality or Activity schools identified by Segers et al. (2011). It would also be consistent with the "dialogic" approach described by Bachkirova, (2016) and Stelter (2014).

The fourth inferred type of 'Performance Management' is the antithesis of a more readily identified type of 'Client-led' coaching and may have some parallels with interventions according to the managerial discourses in coaching described by Western $(2012,2017)$. Managerial discourses for example tend to control the individual and promote the needs of the organization over those of the individual and the emphasis shifts from self-actualisation to roleactualisation (Western, 2017).

While this study suggests a range of descriptions (types) of coaching sessions, these descriptions were often different for the same sessions. One way of understanding these descriptive differences is in terms of differences in "horizons of understanding" (Gadamer, 1996) held by the different participants. From the perspective of the clients, unaccustomed to another person demonstrating the behaviours of active listening, questioning skills, verbal displays of empathy and other coaching skills, the clients might have experienced the sessions as Client-led. They might have also valued the sessions not having been too challenging which would align with similar findings in psychotherapy where clients value sessions which are "smooth" rather than "deep", the converse being the case for therapists (Stiles \& Snow, 1984).

However, from the perspective of the observers, describing the session in relation to professional standards, the sessions often fell short of what they might have expected in terms of an explorative in-depth dialogical process. This suggests the possibility of self-deception on 
the part of the coaches (Bachkirova, 2016). In applying a full range of coaching skills (paraphrasing, restatement, expressing empathy, consciously building rapport, providing support/reassurance, giving verbal encouragement, structuring the session and suggesting solutions), some of the coaches might have appeared to have been too busy to allow the conversation to develop at its own pace and allowing rapport to build naturally.

Another way of making sense of the differences in descriptions could be in terms of the available range and use of vocabulary of the clients and observers. The clients might for example have readily identified references in Q items relating to empathy (Q29) and rapport (Q33) which were associated with Client-led coaching but less so for Q items relating to terms such as "repairs lost connection" (Q31) which would likely have made more sense to the coaches/observers. This may have led to differences in sorting patterns. The clients might have also wished to express satisfaction with their coaches deliberately highlighting Q items associated with Client-led coaching whereas the observers and two coaches conducting sessions who loaded onto factor 2 as well as factor 1 might have wished to express a more professional evaluation. However, the verbal comments provided by the clients tended to support an approach very much aligned with a "Client-led" approach.

Yet another possible way of understanding differences in descriptions is that in the immediacy and intimacy of the face to face exchange, the coaches sensed the positive impact of their approach on the client and this led them to believe that they were adopting a Client-led and valued approach (if qualified for two of the coaches who also loaded significantly onto Factor 2 as well as Factor 1). The observers who were physically distant from the interaction (physically removed in space, time and with no relationship with the client) gave a different description of the session. A sense of Buber's (1999) "I thou" relationship perhaps was only meaningful for the coach and client. In short, there was a difference in how the session was experienced compared to how it was observed. 
Thinking about the implication of the proposed typology for practice, it is important to highlight that the types of coaching identified in this research are congruent with organizational needs expressed for example in the HRD strategies. Drawing on research by Bates \& Chen (2004) and Bates (2002) we can argue that our proposed types of coaching share parallels with the three paradigms of practice in HRD these authors identified: to encourage learning, to increase performance and to enhance meaning in work. For example, Client-led coaching is compatible with the learning paradigm with its emphasis on the client and self-directed learning (andragogy). This approach can be entirely consistent with organizational learning provided there is alignment between learning and the goals of the organization. Process-led coaching is consistent with an inherent behaviourism in the performance paradigm of HRD in the way the coach draws on process, activities and techniques in order to achieve clearly formulated goals. The Performance approach inferred in this study as the antithesis of much coaching practice is when organizational performance takes precedence over individual learning. Holton (2002) describes this approach within an overall performance paradigm as potentially abusive (p. 210). A Dialogic coaching type is consistent with the meaning in work paradigm with its emphasis on meaning rather than performance as an end it itself. In relation to different coaching genres (Cox et al., 2014), Client-led coaching is more aligned to the building of confidence, resourcefulness and leadership development. Process-led coaching is most clearly aligned with performance coaching and provides a structure and focus for the resolution of immediate work challenges. A dialogic approach is a more developmental and psychologically challenging form of coaching in which the client might find outcomes which may or may not align with organizational system performance needs but delivers broader outcomes of value to the individual.

It might be argued that the model proposed in this study is an oversimplification of the coaching process given that there are a range of what on the surface at least, seem very 
different approaches to coaching described in the literature (Palmer and Whybrow, 2007; Passmore, 2007; Cox, et al, 2014). It isn't clear however if these approaches actually share essential similarities. In using Q mode factor analysis as a data reduction method in this study, it is hoped that some fundamental features have been identified in the coaching process. There is clearly a need for expanding this study to evaluate a broader range of coaching practices. However, given the difficulties process researchers face in gaining access to coaching sessions, the involvement of 6 experienced coaches and the "one-off" nature of some coaching sessions provides a promising start of what is hoped to be an on-going programme of research.

\section{Limitations}

While the study did make use of very experienced coaches, the diversity of coaches involved was limited when taking account of the range of coaching approaches (Palmer \& Whybrow, 2007). The one-off nature of some of the sessions coupled with the use of a video-recorder might also have led to a lack of in-depth exploration on the part of the coaches. What also can be considered as a limitation is that the study did not take account of context. The notion of context can include a number of background factors for the session: the broader objectives of coaching (e.g., specific skills, performance or development), the personality type or cognitive style of the client as well as the specific focus of the coaching intervention or the so called 'presenting problem' (e.g., addressing work relationships or initiating a business start-up). Context can also include the broader business climate in which coaching is commissioned. The study by Kauffman \& Hodgetts (2016) for example illustrates how coaches can be particularly sensitive to contextual factors when facilitating sessions. At the same time, the focus on the process is important in its own right if we wish to understand essential elements of the coaching practice in spite of their interdependence and complexity. 
Given the exploratory nature of the research, it is acknowledged that the typology presented in this paper is tentative, being based on only a small and limited range of coaching sessions. It is possible that future research identifies different typologies. However, the identification of an initial typology illustrates how the methodological approach outlined in this paper provides great potential for analysing whole coaching sessions in detail and from multiple perspectives. It also suggests that even experienced coaches might conduct coaching sessions in a way which can give an appearance of a mechanistic/ process-driven approach or one that is very much focused on the client and the relationship rather than encourage depth of exploration.

\section{Future Directions}

It is recommended that future research collect $Q$ sort descriptions of a broader range of coaching traditions, genres and contexts. Future studies could therefore set out to establish replication or to identify alternative typologies. It would be useful to compare the approaches of novice and experienced coaches. More experienced coaches may be more likely to demonstrate managed eclecticism (Clutterbuck, 2010) or model agility (Kauffman and Hodgetts, 2016) although it was interesting to note that our study did involve experienced coaches who might have been expected to have demonstrated model agility. Future studies could also provide more contextual information to observers, including the deliberations of the coach. In this way, the approach of more experienced coaches might be viewed more sympathetically and less process-driven. It would be useful to conduct research that includes clients who might be considered to be at a more advanced level of development (Bachkirova, 2011). This would allow an exploration of how these clients respond to what might be observed as a "Process-led" approach and how their Q Sorts would load onto this type of coaching. The methodology illustrated in this article could be extended to explore interactions 
in coaching supervision in addition to a wide range of workplace interactions including mentoring, performance appraisals, leadership interactions, 360-degree feedback, interviews, sales and consultancy interactions. The strength of Q methodology is its capacity to provide a rich description of interactive processes.

\section{Conclusions and final comments}

The typology described in this article present important ways of conceptualizing differences in the actual practice of coaching. As a first in-depth exploratory and empirical study into the coaching process at the level of a coaching session, it makes a significant contribution to the discipline of coaching by suggesting a tentative typology of coaching based on actual coachclient interactions evaluated from the three essential perspectives. For example, the differences in descriptions of sessions elicited in this article not only provide clarity in coaching practice but also, paradoxically, highlight the relevance of multiple voices (Bachkirova, 2016) in coaching. In doing so, these findings support the relevance of the 'Rashomon conjecture' and re-open this debate in coaching.

A different argument could have been put forward in this paper about the nature of the coaching process had this study not included the perspectives of the coach and client. If only the observer perspective had been included, the study would have given the appearance of two, more or less uncontested types of coaching session: Client-led (sessions 1 and 2); Process-led (sessions 3 and 5) or a mix of both (sessions 4 ad 6). The inclusion of the client and coach perspectives calls into question the ontology of a coaching session as something existing independently of perspective. Both, the client and coach perspectives are fundamental in understanding of the nature of coaching and in the assessment of coaching. There is a parallel here in terms of how leadership might best be understood in terms of the impact it has on 
followers (e.g., theories of transformational leadership, Bass, 1999) rather than in terms of how it might be described in terms of behavioural descriptions.

In terms of practical contribution, the study highlights implications that are relevant to both organizational clients who buy and evaluate coaching and coaching practitioners who are interested in improving their practice. For organizational needs, the typology identified in this empirical investigation offers an opportunity to differentiate what needs are better met by what type of coaching and thus to judge the outcomes of coaching according to the original and most appropriate expectations. What is important for coaches is that they can recognize that they may be using a Client-led, Process-led, Dialogic or a mix of approaches. They can also reflect on whether an emphasis on structuring and directing the process might be impeding depth of exploration or if they are incorporating practices which do not correspond with common understandings of coaching (Performance Management Approach). The descriptions of coaching identified empirically in this study are characteristic of much of what has been described as "run-of-the-mill coaching". This provides reassurance to coaches in the sense that “epiphanies" may not be necessary (de Haan et al., 2010) but at the same time calls into question whether coaching is relationship or technique driven without being particularly explorative and challenging. The possibility is even raised that positive client feedback could lead to self-deception on the part of coaches (Bachkirova, 2015) and thus an additional incentive for their long-term personal and professional development.

\section{References}

Bachkirova, T. (2011). Developmental Coaching: working with the self. Maidenhead: Open University Press.

Bachkirova, T. (2015). Self-deception in coaches: an issue in principle and a challenge for supervision. Coaching: An International Journal of Theory, Research and Practice, 8(1), 
4-19.

Bachkirova, T. (2016). The self of the coach: Conceptualization, issues, and opportunities for practitioner development. Consulting Psychology Journal: Practice and Research, 68(2), 143-156. DOI:10.1037/cpb0000055

Bachkirova, T. (2017). Developing a knowledge base of coaching: Questions to explore. In T. Bachkirova, G. Spence \& D. Drake (Eds.) The SAGE Handbook of Coaching (pp. 23-41). London: Sage.

Bachkirova, T., \& Kauffman, C. (2009). The blind men and the elephant: Using criteria of universality and uniqueness in evaluating our attempts to define coaching. Coaching: An International Journal of Theory, Research and Practice, 2(2), 95-105.

DOI:10.1080/17521880903102381

Bachkirova, T., Sibley, J., \& Myers, A. C. (2015). Developing and applying a new instrument for microanalysis of the coaching process: The coaching process Q set. Human Resource Development Quarterly, 26(4), 431-462. DOI:10.1002/hrdq.21215

Bachkirova, T., Spence, G. \& Drake, D. (2017). Introduction, in T. Bachkirova, G. Spence \& D. Drake (Eds.) The SAGE Handbook of Coaching (pp. 1-20). London: Sage.

Bass, B., M. (1998). Two decades of research and development in transformational leadership, European Journal of Work and Organizational Psychology, 8(1), 9-32.

Bates, R. \& Chen H. (2004). Human resource development value orientations, Human Resource Development International, 7(3), 351-371.

Bates, R. A. (2002). Human resource development objectives. In M. Marquardt (Ed.) UNESCO encyclopaedia of life support systems, New York: United Nations Educational, Scientific, and Cultural Organization.

Blakey, J., \& Day, I. (2012). Challenging Coaching: Going beyond traditional coaching to face the FACTS. London: Nicholas Brealey. 
Block, J. (2008). The Q-sort in character appraisal: Encoding subjective impressions of persons quantitatively. Washington, DC, US: American Psychological Association http://dx.doi.org/10.1037/11748-000

Bono, J. E., Purvanova, R. K., Towler, A. J., \& Peterson, D. B. (2009). A survey of executive coaching practices. Personnel Psychology, 62(2), 361-404. DOI:10.1111/j.17446570.2009. 01142.x

Bowles, S., Cunningham, C. J. L., De La Rosa, G. M., \& Picano, J. (2007). Coaching leaders in middle and executive management: goals, performance, buy-in. Leadership \&amp; Organization Development Journal, 28(5), 388-408.

DOI:10.1108/01437730710761715

Brown, S. R. (1980). Political subjectivity: Applications of $Q$ methodology in political science. New Haven, CT: Yale University Press.

Buber, M. (1999). Elements of the Interhuman. In A. J. Buber (Ed.), Martin Buber on psychology and psychotherapy: essays, letters, and dialogue (Martin Buber Library), (pp.72-88). New York: Syracuse University Press.

Clutterbuck, D. (2010). Coaching reflection: the liberated coach. Coaching: An International Journal of Theory, Research and Practice, 3(1), 73-81.

DOI:10.1080/17521880903102308

Cox, E. (2013). Coaching Understood: A Pragmatic Inquiry into the Coaching Process. London: Sage.

Cox, E., Bachkirova, T. and Clutterbuck, D. (Eds) (2014a). Theoretical traditions and coaching genres: Mapping the territory, Advances in Developing Human Resources, 16(2), 127138.

Cox, E., Bachkirova, T., \& Clutterbuck, D. (2014b). The complete handbook of coaching. London: SAGE. 
de Haan, E. (2008). I doubt therefore I coach: Critical moments in coaching practice. Consulting Psychology Journal: Practice and Research, 60(1), 91-105. DOI:10.1037/10659293.60.1.91

de Haan, E., Bertie, C., Day, A., \& Sills, C. (2010). Critical moments of clients and coaches: A direct-comparison study. International Coaching Psychology Review, 5(2), 109-128. de Haan, E., \& Burger, Y. (2004). Coaching with colleagues - An action guide to one to one learning. Basingstoke; UK: Palgrave Macmillan.

de Haan, E., Culpin, V., \& Curd, J. (2011). Executive Coaching in Practice: What Determines Helpfulness for Clients of Coaching? Ashridge Business School. Retrieved from http://www.erikdehaan.com/wp-content/uploads/2011/08/2011_Executive-coaching-inpractice-what-determines-helpfulness-for-clients-of-coaching.pdf [accessed: 26th October 2014]

de Haan, E., Culpin, V., \& Curd, J. (2011). Executive coaching in practice: what determines helpfulness for clients of coaching? Personnel Review, 40(1), 24-44.

de Haan, E., Duckworth, A., Birch, D., \& Jones, C. (2013). Executive coaching outcome research: The contribution of common factors such as relationship, personality match, and self-efficacy. Consulting Psychology Journal: Practice and Research, 65(1), 40-57.

DOI:10.1037/a0031635

de Haan, E., \& Gannon, J. (2017). The coaching relationship. The SAGE Handbook of Coaching, $11,195-217$.

de Haan, E., \& Nieß, C. (2012). Critical moments in a coaching case study: Illustration of a process research model. Consulting Psychology Journal: Practice and Research, 64(3), 198-224. DOI:10.1037/a0029546

de Haan, E., \& Nieß, C. (2015). Differences between critical moments for clients, coaches, and sponsors of coaching. International Coaching Psychology Review, 10(1), 38-61. 
Egan, T. (2013). Response to Nieminen et al.'s Feature Article on Executive Coaching and Facilitated Multisource Feedback: Toward Better Understanding of a Growing HRD Practice. Human Resources Development Quarterly, 24(2), 177-183.

Ellinger, A. D. \& Kim, S. (2014). Coaching and Human Resource Development. Advances in Developing Human Resources, 16(2), 127-138. DOI:10.1177/1523422313520472

Elliott, R. (2010). Psychotherapy change process research: Realizing the promise. Psychotherapy Research, 20(2), 123-135. DOI: 10. 1080/10503300903470743

Gadamer, H.-G. (1996). Truth and Method (J. Weinsheimer \& D. G. Marshall, Trans.). New York: Continuum

Gessnitzer, S., \& Kauffeld, S. (2015). The working alliance in coaching: Why behavior is the key to success. Journal of Applied Behavioral Science, 51(2), 177-197. DOI: $10.1177 / 0021886315576407$

Grant, A. M. (2012). ROI is a poor measure of coaching success: towards a more holistic approach using a well-being and engagement framework. Coaching: An International Journal of Theory, Research and Practice 5(2), 74-85.

Grant, A.M. (2013). The efficacy of coaching. In J. Passmore, D.B. Petersen \& T. Freire (Eds). The Wiley-Blackwell Handbook of Coaching and Mentoring (pp.15-49) Oxford: WileyBlackwell.

Greif, S. (2010). A New frontier of research and practice: Observation of Coaching Behaviour. Coaching Psychologist, 6(2), 97-105.

Greif, S. (2017). Researching Coaching Outcomes. In T. Bachkirova, G. Spence, \& D. Drake (Eds.), The SAGE Handbook of Coaching (pp. 569-688). London: SAGE.

Hall, D. T., Otazo, K. L., \& Hollenbeck, G. P. (1999). Behind Closed Doors: What Really Happens in Executive Coaching. Organizational Dynamics, 27(3), 39-53.

Hamlin, R. G., Ellinger, A. D., \& Beattie, R. S. (2008). The emergent 'coaching industry': a wake-up call for HRD professionals. Human Resource Development International, 
11(3), 287-305. DOI:10.1080/13678860802102534

Hardy, G.E., and Llewelyn, S. (2015). Introduction to psychotherapy process research. In O. C. G. Gelo,, A. Pritz, A. \& B. Rieken, (Eds), Psychotherapy Research: Foundations, Process, and Outcome. London: Springer (pp.183-194).

Heron, J. (1976). A six-category intervention analysis. British Journal of Guidance \& Counselling, 4(2), 143-155. DOI:10.1080/03069887600760171

Holton, E. F. (2002). Theoretical assumptions underlying the performance paradigm of human resource development. Human Resource Development International, 5(2), 199-215. doi:10.1080/13678860110057629

Ianiro, P., Lehmann-Willenbrock, N., \& Kauffeld, S. (2015). Coaches and Clients in Action: A Sequential Analysis of Interpersonal Coach and Client Behavior. Journal of Business \& Psychology, 30(3), 435-456. DOI:10.1007/s10869-014-9374-5

International Coach Federation (2016). 2016 ICF Global Coaching Study. Retrieved from https://coachfederation.org/app/uploads/2017/12/2016ICFGlobalCoachingStudy Executi veSummary-2.pdf [accessed: 22nd February 2017]

Jones, R. J., Woods, S. A., \& Guillaume, Y. R. F. (2016). The effectiveness of workplace coaching: A meta-analysis of learning and performance outcomes from coaching. Journal of Occupational \& Organizational Psychology, 89(2), 249-277. DOI:10.1111/joop.12119

Joseph, P. (2014). The Person-centred Approach to Coaching. In E. B. Cox, Tatiana \& D. Clutterbuck (Eds.), The Complete Handbook of Coaching (pp. 65-76). London: Sage.

Kauffman \& Hodgetts (2016). Model agility: coaching effectiveness and four perspectives on a case study. Consulting Psychology Journal, 68(2),157-176.

Kemp, T. (2008). Self-management and the coaching relationship: exploring coaching impact beyond models and methods. International Coaching Psychology Review, 3(1), 32-42.

Kurosawa, A. (Writer). (1950). Rashomon. In D. M. P. Company (Producer). Japan. 
L'Abate, L., Frey, J., \& Wagner, V. (1982). Toward a classification of family therapy theories: Further elaborations and implication of the ERA-Aw-C model. Family Therapy, 9(3), 251-262.

Lee, G. (2003). Leadership coaching: From personal insight to organisational performance. London: CIPD Publishing.

MacKie, D. (2015). The effects of client readiness and core self-evaluations on leadership coaching outcomes: a controlled trial. Coaching: An International Journal of Theory, Research and Practice, 8(2), 120-136. DOI:10.1080/17521882.2015.1019532

Mintz, J., Auerbach, A. H., Luborsky, L., \& Johnson, M. (1973). Patient's, therapist's and observers' views of psychotherapy: A "Rashomon" experience or a reasonable consensus? British Journal of Medical Psychology, 46(1), 83-89. DOI:10.1111/j.2044-8341. 1973.tb02233.x

Myers, A., C. (2017). Researching the Coaching Process. In T. Bachkirova, G. Spence, \& D. Drake (Eds.), The SAGE Handbook of Coaching (pp. 589-609). London: SAGE.

Olivero, G., Bane, K. D., \& Kopelman, R. E. (1997). Executive Coaching as a Transfer of Training Tool: Effects on Productivity in a Public Agency. Public Personnel Management, 26(4), 461-469.

Passmore, J. (2007). An integrative model for executive coaching. Consulting Psychology Journal: Practice and Research, 59(1), 68-78. DOI: 10. 1037/1065-9293.59.1.68

Peltier, B. (2009). The Psychology of Executive Coaching: theory and application. Philadelphia, Pa.; Hove: Brunner-Routledge.

Palmer, S., \& Whybrow, A. (Eds) (2007). Handbook of coaching psychology: A guide for practitioners. London: Routledge.

Peterson, D. B. (2009). Coaching and performance management: how can organizations get the greatest value? In S. JW \& L. M (Eds.), Performance Management (pp. 115-156). San Francisco: Jossey-Bass. 
Robson, D. (2011). Measuring value in the coaching relationship. Strategic HR Review, 10(2). DOI:10.1108/shr.2011.37210bab.001

Rogers, J. (2012). Coaching skills: a handbook. Maidenhead: McGraw-Hill Education.

Saunders, M.N.K., Lewis, P., \& Thornhill, A. (2015). Research Methods for Business Students. [online]. Pearson Education Limited. Available from:

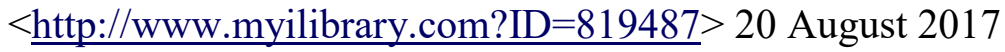

Schmolck, P. (2014). PQMethod (Version 2.35) [Computer Software]. Retrieved from http://schmolck.userweb.mwn.de/qmethod. [accessed: $1^{\text {st }}$ March 2014]

Segers, J., Vloeberghs, D., Henderickx, E., \& Inceoglu, I. (2011). Structuring and Understanding the Coaching Industry: The Coaching Cube. Academy of Management Learning \& Education, 10(2), 204-221. DOI:10.5465/AMLE.2011.62798930

Smither, J. W., London, M., Flautt, R., Vargas, Y., \& Kucine, I. (2003). Can working with an executive coach improve multisource feedback ratings over time? A quasi-experimental field study. Personnel Psychology, 56(1), 23-44. DOI:10.1111/j.17446570.2003.tb00142.x

Spinelli, E., \& Horner, C. (2007). An existential approach to coaching psychology. In P. S \& W. A (Eds.), Handbook of Coaching Psychology: A guide for practitioners (pp. 118-132). London: Routledge.

Stein, I. F. (2009). Which hat am I wearing now? An evidence-based tool for coaching selfreflection. Coaching: An International Journal of Theory, Research and Practice, 2(2), $163-175$.

Stelter, R. (2014). A guide to third generation coaching. Dordrecht: Springer.

Stenner, P., \& Stainton Rogers, R. (2004). Q methodology and qualiquantology: The example of discriminating between emotions. In Z. Tod, B. Nerlich, S. Mckeown, \& D. Clark, (Eds.), Mixing methods in psychology (pp.157-189). London: Routledge.

Stiles, W. B., \& Snow, J. S. (1984). Counseling session impact as viewed by novice counselors 
and their clients. Journal of Counseling Psychology, 31(1), 3-12. DOI:10.1037/00220167.31.1.3

Theeboom, T., Beersma, B., \& Van Vianen, A. E. m. (2014). Does coaching work? A metaanalysis on the effects of coaching on individual level outcomes in an organizational context. Dedicated to furthering research and promoting good practice, 9(1), 1-18. DOI:10.1080/17439760.2013.837499

Watts, S., \& Stenner, P. (2005). Doing Q methodology: theory, method and interpretation. Qualitative Research in Psychology, 2(1), 67-91. DOI:10.1191/1478088705qp022oa

Watts, S., \& Stenner, P. (2012). Doing Q methodological research: Theory, method \& interpretation. London: Sage.

Weiss, I., Rabinowitz, J., \& Spiro, S. (1996). Agreement between therapists and clients in evaluating therapy and its outcomes: Literature review. Administration and Policy in Mental Health, 23(6), 493-511. DOI:10.1007/BF02108686

Western, S. (2012). Coaching and mentoring: a critical text. London: SAGE.

Western, S. (2017). The key discourses of coaching. In T. Bachkirova, G. Spence, \& D. Drake (Eds.), The SAGE Handbook of Coaching (pp. 42-61). London: SAGE.

Wilson, C. (2007). Best practice in performance coaching: A Handbook for Leaders, Coaches, HR Professionals and Organizations, London: Kogan Page. 